\title{
Melatonin secretion in migraine patients: the current state of knowledge
}

\author{
Daniel Zielonka \\ Department of Public Health, Poznan University of Medical Sciences, Poznan, Poland
}

\begin{abstract}
Introduction. In this edition, Zduńska et al. [1] present the results of a pilot study exploring changes in melatonin serum concentration in migraine patients, and the clinical implications of these changes.

Clinical reflections. Melatonin secretion may be altered for several reasons, and migraine is one of those clinical conditions where melatonin secretion can be changed. Correlations between migraine clinical phenotype and melatonin secretion patterns may bring exciting results.

Clinical implications. Alterations in melatonin secretion in migraine has not been explained. Studies which aim at exploring the mechanism(s) of action of melatonin secretion in migraine patients may provide an insight into the pathogenesis of migraine and contribute to effective treatment options.
\end{abstract}

Key words: melatonin, light, migraine

(Neurol Neurochir Pol 2021; 55 (1): 5-7)

Migraine is a common disabling primary headache disorder, ranked in 2010 as the third most prevalent globally. In 2015 , it was the leading cause of disability worldwide in both males and females under the age of $50[2,3]$. Migraine is most often displayed as a paroxysmal headache preceded or not by aura, but it can also be a long-lasting headache and/or headache with several concomitant symptoms [4]. Recent studies have indicated the role of fluctuating excitability, plasticity, and metabolism of cortical neurons involved in the migraine cycle $[5,6]$. Conduction of visual impulses via the hypothalamic region and the thalamic pulvinar nucleus to the visual cortex seems to be responsible for photic hypersensitivity in the premonitory phase of a migraine attack $[7,8]$.

Melatonin is an indolamine synthesised by the pinealocytes in the pineal gland under a neural system's control, including the light sensitive retina and suprachiasmatic nucleus (SCN) $[9,10]$. Melatonin secretion is closely synchronized with the circadian rhythm where light evokes an inhibitory effect on its secretion, moreover, lesions located in the tracts connecting the retina with the pineal gland can disturb the secretion of melatonin [11]. The secretion of melatonin is vital for sleep regulation and its decrease with age may contribute to the worsening of sleep-quality in older people [12].
Melatonin plays a role in the pathophysiology of migraine where it demonstates antimigraine effects via several ways. Neurotransmitter changes and neural pathway modifications, such as restraining nitric oxide synthesis, inhibiting dopamine release, and antagonising glutamate-induced excitotoxicity, are reported mechanisms for melatonin's beneficial effect in migraine [13-16]. Calcitonin gene-related peptide (CGRP) vasodilating effect is responsible for migraine attacks, when melatonin significantly decreases mRNA expression of CGRP release, nitric oxide production, and nitric oxide synthase activity in migraine patients [17].

Interestingly, melatonin has a similar structure to indomethacin; therefore, it is expected to evoke an indomethacin-like analgesic effect [18]. Moreover, the release of $\beta$-endorphins, activation of melatonin receptors, and regulation of $\gamma$-aminobutyric acid receptors are several ways by which melatonin produces its analgesic effects [19]. In the urine of migraine patients, a low level of melatonin metabolites was observed; therefore, a weaker antimigraine effect of melatonin is expected in these patients $[20,21]$.

Several observations on melatonin's antimigraine effects have led scientists to test its beneficial results in patients with migraine, however, recent systemic review yielded conflicting 
outcomes [22]. Hence, extensive research on melatonin's antimigraine effects is yet to be conducted.

To understand melatonin's beneficial effects in migraine, it is important to confirm either disturbances in its secretion or in its metabolism. Zduńska et al. [1] conducted a pilot study which indicated alterations in melatonin secretion profiles and concentration in a migraine group compared to controls. The authors of this study observed insignificantly lower concentrations of melatonin in migraine patients as opposed to the controls, nevertheless, melatonin concentrations became significantly lower with disease duration.

Some similar studies were earlier conducted. First one in 1989 when 93 patients with migraine and 46 controls were examined identifying lower melatonin levels in women patients, notably those with concomitant depression [23]. Respectively in 1994 and in 1995 other authors confirmed this observation in studies carried out in female subjects where they found a significant difference in melatonin levels betwen women with migraine and controls [24, 25]. Importantly, in [24] the authors identified a significant decrease in melatonin levels in patients experiencing a migraine attack. The abovementioned studies were performed in small patient groups, with the next conducted in 2001 on a mostly female group; here again, a melatonin level decrease was confirmed in the migraine group [26]. In 2008 and in a relatively larger study authors observed the lack of the melatonin metabolite (6-sulphatoxymelatonin) difference in the urine of 146 patients (with the exception of 53 patients who experienced a migraine attack on urine collection day) with migraine as compared to 76 controls [21]. Finally, in 2017, a study on 55 migraine patients and 57 controls (both female-preponderant) indicated significantly lower peak melatonin level (sampling at 1 a.m.) in patients with migraine [27].

Intending to provide melatonin-based therapeutic advice for migraine patients, appreciating the contradictory results of previous trials, and the low melatonin side effect risk [22], and based on findings from the above-mentioned studies, this therapeutic approach could be considered in some special patient groups such as women in status migrainosus [28, 29], or these with disturbed light exposure [30,31].

Further exploratory studies concerning the pathophysiology of migraine and melatonin's role are urgently required, as are numerous well-designed trials utilising melatonin for treatment.

\section{References}

1. Zduńska A, Cegielska J, Zduński S, et al. Variability in melatonin concentration in blood serum of patients with episodic migraine: a pilot study. Neurol Neurochir Pol. 2021; 55 (1): 81-90, doi: 10.5603/ /PJNNS.a2020.0095, indexed in Pubmed: 33306192.

2. Vos $T$, Flaxman $A D$, Naghavi $M$, et al. Years lived with disability (YLDs) for 1160 sequelae of 289 diseases and injuries 19902010: a systematic analysis for the Global Burden of Disease Study 2010. Lancet. 2012; 380(9859): 2163-2196, doi: 10.1016/S01406736(12)61729-2, indexed in Pubmed: 23245607.
3. Steiner TJ, Stovner L, Vos T. GBD 2015: migraine is the third cause of disability in under 50s. J Headache Pain. 2016; 17(1): 104, doi: 10.1186/s10194-016-0699-5, indexed in Pubmed: 27844455.

4. Olsen J. Headache Classification Committee of the International Headache Society (IHS) The International Classification of Headache Disorders, 3rd edition. Cephalalgia. 2018; 38(1): 1-211, doi: 10.1177/0333102417738202, indexed in Pubmed: 29368949.

5. Kreczmański P, Wolak T, Lewandowska M, et al. Altered functional brain imaging in migraine patients: BOLD preliminary study in migraine with and without aura. Neurol Neurochir Pol. 2019; 53(4): 304-310, doi: 10.5603/PJNNS.a2019.0035, indexed in Pubmed: 31441496.

6. Rościszewska-Żukowska I, Zając-Mnich M, Janik P. Characteristics and clinical correlates of white matter changes in brain magnetic resonance of migraine females. Neurol Neurochir Pol. 2018; 52(6): 695-703 doi: 10.1016/j.pjnns.2018.09.007, indexed in Pubmed: 30297100.

7. Maniyar FH, Sprenger T, Schankin C, et al. Photic hypersensitivity in the premonitory phase of migraine--a positron emission tomography study. Eur J Neurol. 2014; 21(9): 1178-1183, doi: 10.1111/ ene.12451, indexed in Pubmed: 24780052.

8. Maniyar FH, Sprenger T, Monteith T, et al. Brain activations in the premonitory phase of nitroglycerin-triggered migraine attacks. Brain. 2014; 137(Pt 1): 232-241, doi: 10.1093/brain/awt320, indexed in Pubmed: 24277718.

9. Mays JC, Kelly MC, Coon SL, et al. Single-cell RNA sequencing of the mammalian pineal gland identifies two pinealocyte subtypes and cell type-specific daily patterns of gene expression. PLoS One. 2018; 13(10): e0205883, doi: 10.1371/journal.pone.0205883, indexed in Pubmed: 30347410.

10. Emens JS, Burgess HJ. Effect of Light and Melatonin and Other Melatonin Receptor Agonists on Human Circadian Physiology. Sleep Med Clin. 2015; 10(4): 435-453, doi: 10.1016/j.jsmc.2015.08.001, indexed in Pubmed: 26568121.

11. Zielonka D, Sowiński J, Nowak S, et al. Melatonin and cortisol profiles in patients with pituitary tumors. Neurol Neurochir Pol. 2015; 49(1): 65-69, doi: 10.1016/j.pjnns.2014.12.004, indexed in Pubmed: 25666777 .

12. Kim JH, Duffy JF. Circadian Rhythm Sleep-Wake Disorders in Older Adults. Sleep Med Clin. 2018; 13(1): 39-50, doi: 10.1016/j. jsmc.2017.09.004, indexed in Pubmed: 29412982.

13. Bettahi I, Pozo D, Osuna C, et al. Melatonin reduces nitric oxide synthase activity in rat hypothalamus. J Pineal Res. 1996; 20(4): 205-210, doi: 10.1111/j.1600-079x.1996.tb00260.x, indexed in Pubmed: 8836954.

14. Zisapel N. Melatonin-dopamine interactions: from basic neurochemistry to a clinical setting. Cell Mol Neurobiol. 2001; 21(6): 605-616, doi: 10.1023/a:1015187601628, indexed in Pubmed: 12043836.

15. Ramadan N. The Link Between Glutamate and Migraine. CNS Spectrums. 2014; 8(6): 446-449, doi: 10.1017/s1092852900018757.

16. Peres MFP, Masruha MR, Zukerman E, et al. Potential therapeutic use of melatonin in migraine and other headache disorders. Expert Opin Investig Drugs. 2006; 15(4): 367-375, doi: 10.1517/13543784.15.4.367, indexed in Pubmed: 16548786.

17. Ansari M, Karkhaneh A, Kheirollahi A, et al. The effect of melatonin on gene expression of calcitonin gene-related peptide and some proinflammatory mediators in patients with pure menstrual migraine. Acta Neurol Belg. 2017; 117(3): 677-685, doi: 10.1007/s13760-0170803-x, indexed in Pubmed: 28584969.

18. Singh M, Jadhav HR. Melatonin: functions and ligands. Drug Discov Today. 2014; 19(9): 1410-1418, doi: 10.1016/j.drudis.2014.04.014, indexed in Pubmed: 24792719. 
19. Danilov A, Kurganova J, Kurganova JuM, et al. [Melatonin in chronic pain syndromes]. Zh Nevrol Psikhiatr Im S S Korsakova. 2015; 115 (10 Pt 2): 47-54, doi: 10.17116/jnevro201511510247-54, indexed in Pubmed: 26977916.

20. Masruha MR, Lin J, de Souza Vieira DS, et al. Urinary 6-sulphatoxymelatonin levels are depressed in chronic migraine and several comorbidities. Headache. 2010; 50(3): 413-419, doi: 10.1111/j.1526-4610.2009.01547.x, indexed in Pubmed: 19817880.

21. Masruha MR, de Souza Vieira DS, Minett TS, et al. Low urinary 6-sulphatoxymelatonin concentrations in acute migraine. J Headache Pain. 2008; 9(4): 221-224, doi: 10.1007/s10194-008-0047-5, indexed in Pubmed: 18594760.

22. Long $\mathrm{R}$, Zhu $\mathrm{Y}$, Zhou $\mathrm{S}$. Therapeutic role of melatonin in migraine prophylaxis: A systematic review. Medicine (Baltimore). 2019; 98(3): e14099, doi: 10.1097/MD.0000000000014099, indexed in Pubmed: 30653130.

23. Claustrat B, Loisy C, Brun J, et al. Nocturnal plasma melatonin levels in migraine: a preliminary report. Headache. 1989; 29(4): 242-245, doi: 10.1111/j.1526-4610.1989.hed22904242.x, indexed in Pubmed: 2714976.

24. Murialdo G, Fonzi S, Costelli P, et al. Urinary melatonin excretion throughout the ovarian cycle in menstrually related migraine. Cephalalgia. 1994; 14(3): 205-209, doi: 10.1046/j.1468-2982.1994.014003205.x, indexed in Pubmed: 7954740.

25. Brun J, Claustrat B, Saddier P, et al. Nocturnal melatonin excretion is decreased in patients with migraine without aura attacks associated with menses. Cephalalgia. 1995; 15(2): 136-9; discussion 79, doi: 10.1046/j.1468-2982.1995.015002136.x, indexed in Pubmed: 7641249.
26. Peres MF, Sanchez del Rio M, Seabra ML, et al. Hypothalamic involvement in chronic migraine. J Neurol Neurosurg Psychiatry. 2001; 71(6): 747-751, doi: 10.1136/jnnp.71.6.747, indexed in Pubmed: 11723194.

27. Kozak HH, Boysan M, Uca AU, et al. Sleep quality, morningness-eveningness preference, mood profile, and levels of serum melatonin in migraine patients: a case-control study. Acta Neurol Belg. 2017; 117(1): 111-119, doi: 10.1007/s13760-016-0723-1, indexed in Pubmed: 27858294.

28. Claustrat B, Brun J, Geoffriau M, et al. Nocturnal plasma melatonin profile and melatonin kinetics during infusion in status migrainosus. Cephalalgia. 1997; 17(4): 511-7; discussion 487, doi: 10.1046/j.1468-2982.1997.1704511.x, indexed in Pubmed: 9209772.

29. Chądzyński P, Kacprzak A, Domitrz W, et al. Migraine headache facilitators in a population of Polish women and their association with migraine occurrence - preliminary results. Neurol Neurochir Pol. 2019; 53(5): 377-383, doi: 10.5603/PJNNS.a2019.0044, indexed in Pubmed: 31592536.

30. Salvesen R, Bekkelund SI. Migraine, as compared to other headaches, is worse during midnight-sun summer than during polar night. A questionnaire study in an Arctic population. Headache. 2000; 40(10): 824-829, doi: 10.1046/j.1526-4610.2000.00149.x, indexed in Pubmed: 11135027.

31. Claustrat B, Brun J, Chiquet $\mathrm{C}$, et al. Melatonin secretion is supersensitive to light in migraine. Cephalalgia. 2004; 24(2): 128-133, doi: 10.1111/j.1468-2982.2004.00645.x, indexed in Pubmed: 14728708 . 